\title{
University-Community Engagement: What does it mean?
}

JENNY ONYX

T want to reflect on the nature of Community-University

Lengagement, its role, challenges and achievements. In this I start with 'engagement' and what that might mean in the context of a university-based research centre. There are, of course, many forms of engagement, but I wish to focus specifically on engagement as coproduction of knowledge. In this, our partner in the co-production of knowledge is the community, or rather civil society. I re-examine the nature of community, and the role of civil society in today's society. The article then outlines one significant research programme that emerged from the work of a university research centre, the Centre for Australian Community Organisations and Management (CACOM), at the University of Technology, Sydney. This research - namely the story of social capital research - was initiated by a request from community partners and was carried out in collaboration with them. 
The research programme led to several significant research projects which have had a major impact on theory and public policy. It challenges the notion of the university as 'expert' and illustrates the co-production of knowledge. The article concludes by discussing the various roles that the university can play within the co-production of research knowledge with the community: as collaborator in the research process itself; as mediator in the development of linking social capital between community and more powerful players; and as the potential site for independent critical analysis.

\section{THE NATURE OF ENGAGEMENT}

There are a number of significant forms of Community-University engagement, all of which occur within the University of Technology, Sydney. These include various forms of work-based learning, industry placement programmes, and student volunteer projects. However, this paper focuses on one form of engagement that has received little attention. That is the engagement between a university research centre and the community sector, or civil society.

The university research centre is typically regarded as the primary site for the advancement of knowledge, in which the academic or research fellow takes the role of 'expert' in identifying research questions, developing programmes of research and disseminating findings, primarily to an audience of peers, but ultimately to the wider community (Eyerman 1994; see also Goldfarb 1998). In this role of 'expert' the University researcher is called upon to provide expert advice to government and industry. It is also possible that the university research centre may become the arena in which the intellectual tradition of social critique may flourish, as Eyerman notes but with some scepticism:

One such context, both local and global, is the university and other institutions of higher learning. The idea of higher learning has provided 'intellectuals' with grounding for their claim to expert knowledge, and thus helped reproduce as well as legitimate the expert-professional tradition, but it has also provided grounding, either as a counterfoil or as an inspiration, for other intellectual traditions. This is then one context which could serve as a space for the 
emergence of a new generation of critical intellectuals.

(Eyerman 1994, p. 192)

In any case, the intellectual, even those who maintain a critical independence, remain within the expert-professional tradition and are therefore seen as knowledge producers, or at least as gatekeepers and arbiters of what counts as 'knowledge'. It is a very top-down view of expert knowledge.

Gallopin et al. (1999) suggest that the leading forms of scientific knowledge have become 'industrialised' or 'incorporated'. They refer to a process whereby scientific knowledge has been increasingly separated from 'public knowledge', through patent systems, increasingly specialized technology-based knowledge and the creation of 'expert' knowledge systems, which alienate the lay members of the society for whom they seek scientific knowledge. The increasingly codified scientific knowledge is no longer accessible to the 'lay' public, opening a case for uncertainty and skepticism regarding the content and validity of 'scientific' knowledge claims.

An alternative view sees knowledge as socially constructed within a wider arena of engagement. In the new form of reflexive modernization, people are less trusting of expert knowledge, and new forms of 'regulation' emerge, being either formal reflexive regulation, such as self-commitments, mediation processes and voluntary agreements, or informal reflexive regulation, such as networks and informal agreements. These new forms of regulation are 'shaping society from below' and their dynamics, and those of attendant disputes, are the sub-politics of the 'risk society' (Beck 1999, pp. 37-38). In this context, lay knowledge, not techno-scientific knowledge, is the bearer of the 'revolutionary reflexive consciousness'.

The very production of knowledge itself has thus shifted. Gibbons et al. (1994) identify two modes of knowledge production. While mode one refers to the conventional production of scientificexpert knowledge, mode two is much more complex. Consistent with the social construction of knowledge, it refers to knowledge produced in the context of its application:

Knowledge is always produced under an aspect of continuous negotiation and it will not be produced unless and until the interests of the various actors are included. (Gibbons et al. 1994, p. 4) 
Such knowledge generation is transdisciplinary within a problemsolving framework and involves both empirical and theoretical components. It is dynamic, and its diffusion occurs initially in the very process of its production. Such knowledge production is likely to occur through multiple sites, and is certainly no longer the privileged possession of the university.

\section{THE NATURE OF 'COMMUNITY'}

There has always been community, since the beginning of human social formation. As far back as recorded history allows us to see, there are numerous examples of charitable works performed by churches and other formal or informal organizations. There have always been efforts by citizens to mobilize for a common cause, be it the Guilds of the middle ages, or a socio-political movement for human rights. These mobilizations all refer to arenas of purposive collective action around shared interests and values, but operating outside the institutional forms of state, market and family (Howell 2006). They may, but need not, constitute formal incorporated nonprofit organizations. They are usually initiated through loose, informal networks that gradually crystallize into social movements or formal organizational structures.

The concept of community has been roundly critiqued by sociologists as largely meaningless (Bell \& Newby 1974).

Nonetheless, it continues to hold central meaning in everyday discourse and in academic analysis. We all live in some form of community or overlapping communities. These communities have one thing in common; they all comprise ongoing, face-to-face relationships with significant others. ${ }^{1}$ Communities may be either local or extra-local:

When we say communities are local we mean that they are limited to a specific, symbolically defined, geographic area. We emphasize that 'locality' is symbolic, because individual members are likely to have different notions about what defines the geographic area ... Locality is important because it generally defines the boundaries of our informal social

\footnotetext{
${ }^{1}$ The matter of online community is a matter of recent inquiry, note, for example, Appadurai (1990).
} 
lives, suggesting that interpersonal networks will be closed and bounded. (Milofsy \& Hunter 1994)

Most people interact not only within a local community, but also within various extra-local communities of interest. Relationships are defined and conditioned by cultural, social, economic and political systems operating at regional, national, and increasingly at international levels. The social frame of reference may be an ethnic community, for example, or a professional community with indeterminate physical boundaries. In either case the term 'community' as applied has important core meaning attributes, but fuzzy boundaries in terms of exactly who is or is not included.

Within each of these communities, whether local or extra-local, much of the work of the community occurs directly and immediately, without any sort of formal, structural intervention. The acts of simple neighbourliness are of this sort. A neighbour is sick so we bring in a bowl of soup. A neighbour's child wanders down the street and we take her home. But other exchanges need to be formalized in some way, usually because it is necessary to set up some sort of organizational structure so that the exchange can continue into the future. Our disabled children will need support long into the future. It is too important to leave to the chance assistance of a neighbour, and too heavy a burden to bear alone. So we form organizations whose brief it is to care for these children. This leads to a realization of other needs, for example to educate the community, change legislation, and create a different climate so that disabled children can have better life chances. So we, the parents and citizens, band together with others, including concerned professionals, to form advocacy or political lobby groups. These groups may begin as informal networks, but find the need to formalize their structure as they evolve and acquire and use resources in their mission.

So civil society is made up of the thousands of networks and organizations, of various degrees of formality, that our communities have created as instruments to pursue what some people have identified as important ongoing work of the community. They are as different from each other as their origins and purpose suggest. But, by and large they carry some common values. They are non-profit; they do not set out to make a profit to further the economic advantage of any person or group of people. They are voluntary; they are formed out of the free and willing association of their members. 
They are non-government; they are explicitly independent of any party political or state interest. They are task oriented; they are explicitly formed to carry out important community work. They seek social change; they reflect and attempt to realize a collective vision of a better world.

The multitude of community, civil society organizations can generally be categorized according to their role. The majority are concerned with direct service delivery to a specified category of (usually disadvantaged) people. Some organizations carry the task of political advocacy. Others are more concerned with community development. Community development is particularly important because it is about the enhancement of the whole community and its citizens. Community development activities operate according to threefold principles:

- decision making by those most affected by outcomes of the decision - the subsidiarity principle

- personal empowerment and control by individual citizens over their own life - the empowerment principle

- the development of ongoing structures and processes by which groups can meet their own needs - the structural principle.

\section{THE Formal STUdy OF CIVIL SOCIETY}

Until very recently there was virtually no presence of the study of civil society or its organizations within any university. Consequently there was little understanding of its size or importance within the larger society. Even the name used varies widely. Terms used for civil society organizations include: the non-profit sector, the voluntary sector, the third sector, the community sector, or nongovernment organizations (NGOs). Each of these terms refers to much the same phenomenon, but emphasizes one aspect of the sector. Only in the last fifteen years has there been an attempt, through the Johns Hopkins Comparative Nonprofit Sector Project (www.jhu.edu/cnp) and more recently through the international civil society organization CIVICUS (www.civicus.org), to systematically measure the size and capacity of the third sector, that is, of legally recognized non-profit organizations in a country.

The Johns Hopkins project now includes comparative and detailed data for thirty six countries. The findings are astounding. Far 
from being a sector of minor importance and poor resources, civil society in most countries includes many thousands of organizations, involving millions of volunteers and paid workers, and representing some 5.4 per cent of GDP (Salamon, Sokolowski \& Associates 2004). In Australia for example, as of 1996, there were an estimated 700000 civil society organizations of which 320000 were incorporated (had a formal structure) and 34000 of which employed staff. There were 460000 full-time equivalent workers comprising 7.6 per cent of the Australian workforce. In addition, 2.3 million Australians volunteered a total of 374 million hours, amounting to a further 217000 full-time equivalent staff (Lyons 2001, p. 17).

However, the third sector is unlike either the state or the market. Government draws its power and resources from the political process and taxation. Business, for-profits, draw their power and resources from the market itself, from the capacity to sell for profit. Civil society organizations, as the third sector, draw their power and resources from the people, from the capacity to mobilize, from voluntary donations of time and money and from contributions from the other two sectors. It is more variable in its forms, being often driven by small groups of citizens in pursuit of a vision. Often that vision has revolved around issues of social justice, and attempts to improve the lot of the disadvantaged and marginalized. Perhaps for this reason, much of the third sector has remained opaque to the public eye, seen as an admirable but nonetheless small, impoverished and insignificant aspect of society.

In Australia, as elsewhere, there was no attempt at the national level to include the non-profit sector in any regular census until recently. One may reflect that such disinterest in civil society was entrenched within welfare state ideologies that focused on the central role of the state to meet all human and social justice needs. But it was equally entrenched in the ideology of the new right, based on public choice theory and the fundamental assumption of individualized selfinterest.

Be that as it may, few universities had any formal engagement with community in terms of a dedicated research centre until the 1990s, either in the US, UK or Australia. In Australia, the first ever university course in community management was established at the University of Technology, Sydney (UTS) in the mid 1980s, followed shortly thereafter by the formation of CACOM, the first Australian research centre, whose mission was and still is to enhance the 
Australian Community Sector and its management through research, training, publications, seminars and conferences. Later, in 1996,

CACOM was joined at UTS by Shopfront, which represented a forum for community projects involving UTS students and staff, from which the community benefited, and students gained formal course credit.

During the same period, there was a proliferation of similar centres across the US, Canada and UK and the development of an international organization: the International Society for Third-sector Research (ISTR), which holds biennial international conferences.

\section{The Story OF Social CAPITAl Research}

In order to gain an insight into what can be gained from such a formal research commitment to community, one particular research programme will be described from within CACOM. This is the story of a research programme which has had a continuing strong effect on Australian academic thought and on public policy, but which was initiated and driven by a practitioner research agenda. Social capital research arose initially out of a political need to defend community development programmes. As one consequence of economic rationalist policies, all programmes were required to demonstrate measurable outcomes. Those that could not lost their funding. As one anonymous government Minister was known to have articulated: 'if you can't measure it you can't manage it, and we won't fund it' (Kenny, 1994).

While the tradition of community development is as old as human habitation, community development in Australia, as elsewhere in post-industrial countries, found new impetus from the rights movements of the 1960s and 1970s in the form of a determination to remove all injustice, poverty and oppression, by empowering the people to participate in their own development. The rights discourse was quite different from the earlier 'charity' model. Charity was offered to 'the deserving poor' by the privileged of society. The community development of the 1970s emerged as a philosophy, and as a political strategy for empowerment and social change. It was about bottom-up processes of change and action, about the right of people to have a say in decisions that affected their lives, about participation, mutual support, collective action and the demand for resources. It was about self-help too, but at a collective rather than an individual level. It was recognised that if social 
structures had created inequality and disadvantage, then it was the responsibility of the larger society to provide the resources to redress them (Kenny 1994).

As a consequence, governments at State and Commonwealth levels attempted to respond to community demands by providing resources, both structural and financial, for hundreds of community development initiatives. Demands for funding increased throughout the 1980s as new social problems were identified. But with the new funding came greater demands for accountability, and for evidence of effective use of that funding. It became necessary to demonstrate the impact of community development programmes. Those that could not do so were in danger of losing funding.

Finally, in 1994, CACOM at UTS was asked by some of its industry partners to use its research expertise to find a way to help small local community development functions survive. Basically, the request was made to find ways to measure community development, and to develop performance indicators so that organisations could provide evidence to funding bodies demonstrating that community development was real, measurable, produced positive outcomes for the community and, therefore, worth funding. Although there was unlikely to be major university funding available in the political climate of the day to carry out such research, the Faculty of Business made a small grant and the Local Community Services Association of NSW (LCSA) agreed to contribute its own networking and volunteer resources. As the peak body for small local community development organizations, such as neighbourhood centres, this constituted a considerable resource. CACOM agreed to assist.

Like many community sector research projects this began with a very definite practical purpose, but a rather vague conceptual framework. In order to try and explicate the research question more clearly, a series of workshops / reflective dialogues were held both with people in the field and with academics. The early workshops were centred around the question, 'What would a healthy "developing" community look like?' (Onyx 1996). ${ }^{2}$

At one of these workshops, Eva Cox introduced the term 'social capital'. She was preparing her much-respected Boyer lectures at the

\footnotetext{
${ }^{2}$ The story of social capital research is also recorded in Onyx (2003).
} 
time on the topic of A Truly Civil Society (Cox 1995). Robert Putnam had just published his groundbreaking book on Making Democracy Work (Putnam, Leonardi \& Nanetti 1993). It became clear that we needed to measure social capital. The concept sounded hard-headed and measurable, the sort of language that bureaucrats might be interested in. But what was it?

As we pursued the issue of social capital through the emerging literature and through our own discussions, it became clear that the concept needed considerable explication before we could begin to measure it. So the empirical research question became one of 'What is the conceptual structure/nature of social capital (what is it)?'. The question led to the development of an instrument incorporating all those items that may be relevant. The resulting questionnaire was completed by over one thousand citizens across five communities in NSW. It was factor analysed, refined into the core items, which comprised a social capital factor as well as eight identifiable separate factors, and the results published. The resulting survey instrument has since been used and replicated many times and the social capital scale has proved very useful, particularly in a local government context. $^{3}$

The publication of the survey results completed one phase of the research cycle. However, it is interesting to reflect on subsequent events. Like all good research, the survey raised far more questions than it answered. It generated a whole new set of research questions to be pursued, many of which required a quite different methodology. The results also impacted on the real world of social policy and organizational practice.

For example, we found that volunteers score among the highest of all groups on many of the social capital dimensions. Further empirical and theoretical work has tried to explicate the importance of volunteering for the generation of social capital. Indeed, Onyx and Leonard (2000a) proposed a theoretical model that placed volunteering at the heart of social capital. Leonard and Onyx were successful in obtaining university research funding to pursue the role of volunteering in the generation of social capital. This time the

\footnotetext{
${ }^{3}$ The survey results are presented in Onyx and Bullen (2000). Later validation of the scale in the US can be found in O'Brien, Burdsal and Molgaard (2004).
} 
research was done with industry partners that included both government departments and a peak community organization. That second study demonstrated the crucial role of volunteers in maintaining rural communities in particular (Onyx, Leonard \& Hayward-Brown 2003).

It also identified that volunteers play at least three roles within the community. First, volunteers play a key role as community builders, in developing organizations and services within the local community. This role is particularly important in rural areas which may not otherwise access crucial recreational or social services. Second, volunteers play a mediating role in community networks, particularly between professional and lay networks. The study found that the volunteer is regarded as a kind of para-professional, one that is positioned in the overlap between the professional world and the community world. The volunteer is not a professional, but an ordinary citizen in the local community. But by virtue of their training and experience within the organization, they have access to a great deal of information that is useful to the community. In seeking access to that information, people may feel more comfortable with asking a friend than approaching formal, professional sources. Third, given their key location in community networks, volunteers also play a key role in maintaining bonding and developing bridging links with other organizations and communities of interest. Given this key locational position, they may be instrumental in creating, or alternately obstructing, broader community networks. That is, they play a gatekeeper role in network building, a role that may facilitate or impede inclusivity within the wider community.

Social capital is certainly not limited to any one segment of the population. One research study by a student of CACOM who is also a community worker found that older immigrant groups from nonEnglish speaking background score in the mid-range on most social capital dimensions, including 'Community Connections' (Brown, Onyx \& Bullen 1999). On the other hand, as Bullen and Onyx (1999) identified, Family Support Service clients have the lowest scores, compared with all other groups, on all social capital dimensions except 'Tolerance of Diversity'. This group of highly stressed, vulnerable people has minimal access to the social capital of the communities in which they live.

Researchers from CACOM and partner Universities went on to identify other implications of social capital and the community, in 
particular, the relationship between social capital (bonding and bridging) and community capacity building. Preliminary fieldwork in Sweden was published in another CACOM working paper (Onyx \& Leonard 2000b). Subsequently CACOM was successful in obtaining other research funding to explore the implications of social capital in rural Australian and Canadian towns.

\section{THE IMPLICATIONS OF THIS STORY}

It is interesting to trace the sequence of events over the ten years of this research programme. At one level, it is a conventional university research programme, supported by traditional research funding sources. However, there are several significant factors that set it somewhat apart:

- the impetus for the programme came not from academia, but from the community itself, specifically from small community organizations requesting assistance

- the initial research could not attract adequate research funding as it lay outside the mainstream disciplinary interest of the time (that changed later)

- the research at each point was done with the support of industry partners, that is, with community-based organizations, all of whom contributed considerable in-kind resources of time and labour. The research could not have been done without this engagement by the community partners

- the development of the research questions, the methods and the interpretation of the findings was a collaborative process, involving both academics and community practitioners.

The kind of University-Community engagement illustrated by the social capital research programme involved multiple stakeholder partnerships. Each was positioned differently with respect to the research process, and was, therefore, able to contribute its own unique perspective, knowledge base and implicit resources. This was indeed social and human capital put to maximum effect, producing a far richer picture than any one approach could have provided. In all of this, the university contribution was significant, in terms of the research expertise and knowledge of the literature provided by the 
participating academics, as well as the broader research infrastructure that the university can access.

University research is also (ideally) seen as value neutral and research findings deemed more likely to be valid. This is important in the political context in which the community is seeking government funding for its programmes. Within the sub-politics of funding proposals, evidence constructed and presented by the organization seeking funding is likely to be regarded as self-serving and unreliable, while (the same) evidence constructed and presented by a university is more likely to be regarded as credible. So the role of the university is important. However, in the example cited, and indeed in any true University-Community engagement, the role of the university was not one of largess, donating its knowledge and expertise to the supplicant community. It was a much more dynamic and reflexive process, in which the knowledge grew out of the interaction between university and community. Both contributed and therefore the emergent knowledge could not have occurred without the interaction.

This process challenges the nature of knowledge itself as traditionally constructed, and approximates Gibbons et al. (1994) mode two knowledge production. The knowledge required to understand social capital and community capacity building is not located within a rarefied scholarship. It is the collective construction of multiple, differently positioned minds collaborating and sharing their specific perspectives. The knowledge was not the property of the university or of the community, but an emergent product of the engagement.

\section{The University As Mediator}

This is not to deny the potential leadership role of the university. In the example cited above, the initiative came from the community in the first instance, but it was the action of the university that placed social capital on the social policy map. In some cases the university may take on the role of social entrepreneur, establishing a community/training/ research function outside the university itself, on the model of the teaching hospital. Historically, a number of Social Work Schools have established and maintained Community Houses in this way.

In other contexts, the university may play the role of broker or mediator. To use the language of social capital again, social capital is 
normally based on collaborative networks among equals. These ties may be close (as in bonding social capital) or loose (as in bridging social capital). But there is also 'linking social capital' which entails networks among those with unequal power (Woolcock \& Narayan 2000). Such networks are crucial in enabling the relatively powerless to access knowledge and resources from the relatively powerful. They frequently require the mediation of power relationships in order to allow collaborative action to facilitate cross-group trust and cooperation. As this takes time and a significant amount of interaction among individuals and groups, the development of linking social capital requires long-term commitment by all parties.

The process may be facilitated by a neutral, but trusted, third party who is able to mediate and negotiate some of the politically sensitive issues that divide. Universities sometimes play that role. In one example, in South Africa, a university work-based learning initiative enabled the development of community primary health services in disadvantaged areas, and involved the negotiation at many points with both the community and with the Government Health Department (Dovey \& Onyx 2000). Again, it was a multistakeholder process in which knowledge was emergent and shared across the normally intractable divides of community, government and academics. In this process, the university was able to play an important mediating role, both in showcasing aspects of the programme to the government department, but also in supporting the application of funding for the programme to continue. Within the communities themselves, the health professional students were able to gain enhanced authority by virtue of university support, for the introduction of new primary health initiatives, particularly where there was some traditional resistance to these initiatives.

\section{THE UNIVERSITY As SITE For INTELLECTUAL DELIBERATION}

Goldfarb identifies the university as the natural location for intellectual deliberation. He also notes the function of critical deliberation is in danger of being subverted by the new, and selfinterested, professionalism. Yet it remains possible for academic intellectuals to maintain a critical independence from wider political and economic forces, at least to some extent. For Goldfarb, the task is complex but important. 
Intellectuals help societies talk about their problems. They contribute to a democratic life when they civilize political contestation and when they subvert complacent consensus ... Intellectuals are key democratic agents as they stimulate informed discussion about pressing social problems, fulfilling this role by cultivating civility in public life and promoting the subversion of restrictive common sense. (Goldfarb 1998, p. 1)

Goldfarb does not see the university as the only, or even the primary, site for intellectual activity. Civil society is perhaps equally important, at least in some times and places. He defines civil society very broadly as that which develops when people 'act as if they lived in a free society' and in the process produce one. The essence is always one of critical independence from the state, the market and the family. While universities are not always able to maintain this critical independence, a university research centre may attempt to do so, by stimulating wider social and economic debate, by providing a forum for such critical engagement both inside and outside the university, and by disseminating the products of such deliberation. While the social capital research programme could hardly be seen as radical, it did have the desired effect of challenging the prevailing limited economic rationalist view of social policy.

\section{CONCLUSION}

University-Community engagement may now have found its time. In the postmodern world of complex ideas and shifting priorities, it is crucial that civil society be recognized as central to understanding the current discourses of government and society. The problems and issues of modern life involve many stakeholders, and an understanding of them. The development of new knowledge will necessarily be an emergent phenomenon involving dialogue and collaborative action by all stakeholders. The university is well positioned to engage in this process, not as received 'expert' but as one player that can contribute its knowledge and resources, sometimes in response to community initiative, sometimes taking a leadership role and sometimes providing a brokerage or mediating role representing the community interests before more powerful state or market interests. There is an incipient scholarship of engagement 
emerging. Once articulated, a discourse of University-Community engagement will inevitably lead to new insights and more effective programmes of research, training and policy development.

\section{REFERENCES}

Appadurai, A 1990, 'Disjuncture and difference in the global cultural economy', in M Featherstone (ed.), Global culture: Nationalism, globalization and modernity, Sage, London.

Beck, U 1999, World risk society, Polity Press, Cambridge.

Bell, C \& Newby, H 1974, 'Introduction', in C Bell \& H Newby (eds), The sociology of community, Frank Cass, London.

Brown, K, Onyx, J \& Bullen, P 1999, 'Social capital and seniors networks in a multicultural context', Third Sector Review, vol. 5, no. 2, pp. 57-69.

Bullen, P \& Onyx, J 1999, Social capital: Family support services and neighbourhood and community centres in NSW, Local Community Services Association of NSW \& Family Support Services Association on NSW, Sydney.

Cox, E 1995, A truly civil society, Boyer Lectures, ABC Books, Sydney.

Dovey, K \& Onyx, J 2000, 'The long road to reconstruction: Work-based learning, social capital and the transformation of a South African Health Service', unpublished paper, UTS, Sydney.

Eyerman, R 1994, Between culture and politics; Intellectuals in modern society, Polity Press, Cambridge.

Gallopin, G, Funtowicz, S, O'Connor, M \& Ravetz, J 2001, 'Science for the twenty-first century: From social contract to the scientific core', International Journal Social Science, vol. 168, pp. 219-229.

Gibbons, M, Limoges, C, Nowotny, H, Schwartzman, S, Scott, P, \& Trow, M 1994, The new production of knowledge: The dynamics of science and research in contemporary societies, Sage, London.

Goldfarb, J 1998, Civility and subversion: The intellectual in democratic society, Cambridge University Press, New York.

Howell, J 2006, 'The global war on terror, development and civil society', Journal of International Development, vol. 18, pp. 121-135.

Kenny, S 1994, Developing communities for the future: Community development in Australia, Thomas Nelson, Melbourne.

Lyons, M 2001, Third sector: The contribution of nonprofit and cooperative enterprise in Australia, Allen \& Unwin, Crows Nest. 
Milofsky, C \& Hunter, A 1994, Where nonprofits come from: A theory of organizational emergence, 1994 ARNOVA Conference, San Francisco.

O'Brien, M, Burdsal, C, \& Molgaard, C 2004, 'Further development of an Australian-based measure of social capital in a US sample', Social Science and Medicine, vol. 59, pp. 1207-1217.

Onyx, J 1996, 'Social capital: Theory and measurement', Working paper series no. 34, Centre for Australian Community Organisations and Management, University of Technology, Sydney.

Onyx, J 2003, 'The story of social capital research', Third Sector Review, vol. 9, no. 2, pp. 53-64.

Onyx, J \& Bullen, P 2000, 'The different faces of social capital in NSW Australia', in P Dekker \& E Uslander (eds), Social capital and participation in everyday life, Routledge, London.

Onyx, J \& Leonard, R 2000a, 'Women, volunteering and social capital', in J Warburton \& M Oppenheimer (eds), Volunteers and volunteering, Federation Press, Sydney.

Onyx, J \& Leonard, R 2000b, 'Rural renewal and social capital: The case of Sweden and Australia', Working paper no. 46, Centre for Australian Community Organisations and Management, University of Technology, Sydney.

Onyx, J, Leonard, R \& Hayward-Brown, H 2003, 'The special position of volunteers in the formation of social capital', Voluntary Action, vol. 6, no. 1, pp. 59-74.

Putman, R, Leonardi, R \& Nanetti, R 1993, Making democracy work: Civic traditions in modern Italy, Princeton University Press, Princeton, New Jersey.

Salamon, L, Sokolowski, W \& Associates 2004, Global civil society: Dimensions of the nonprofit sector, Kumarian Press, Bloomfield.

Woolcock, M \& Narayan, D 2000, 'Social capital: Implications for development theory, research and policy', World Bank Research Observer, vol. 15, no. 2, pp. 225-250. 